\title{
Chapter 7 \\ Seasonality in Gum and Honeydew Feeding in Gray Mouse Lemurs
}

\author{
Marine Joly-Radko and Elke Zimmermann
}

\begin{abstract}
Exudates represent an important component of the natural diets of small-bodied primates. For mouse lemurs, the impact of forest type and seasonal predictability on gum consumption has recently been intensively investigated. The goal of our study was to extend our knowledge regarding the seasonality of feeding ecology of Microcebus murinus, first, to investigate the relative consumption of gum and hemipteran honeydew, a sap-derived product, and, second to assess respective foraging strategies in a highly seasonal and quite predictable environment. We hypothesized that (1) food resources vary according to the season, (2) gum and honeydew represent keystone food resources during periods of food scarcity, and (3) lemurs revisit productive stationary feeding sites during the period of food scarcity. We studied gray mouse lemurs in the dry deciduous forest of the Ankarafantsika National Park in northwestern Madagascar. We radiocollared seven $M$. murinus females and performed focal observations on their feeding behavior during the end of the dry and the beginning of the rainy season. During the dry season, the period of food scarcity, mouse lemurs mainly consumed gum and honeydew. Subjects revisited the same feeding sites within the same and over several nights. During the rainy season, the period of food abundance, lemurs consumed mainly nectar from shrub flowers and did not show gum or honeydew feeding. To our knowledge, the consumption of honeydew by lemurs is a unique case of sap feeding by proxy in a mammal. Further investigations will focus on the characterization of the ecological consequences of such an interaction between mouse lemurs, hemipteran larvae, and host plants.
\end{abstract}

\footnotetext{
M. Joly-Radko $(\bowtie)$

Institut fuer Zoologie, Tieraerztliche Hochschule Hannover, Buenteweg 17,

Hannover 30559, Germany

e-mail: marine.joly@tiho-hannover.de
} 


\section{Introduction}

Exudates represent an important food category in the natural diet of small-bodied primates (Nash 1986). Exudate is a global term under which one may distinguish different plant fluids as resin, latex, gum, and sap (Bearder and Martin 1980). Resin and latex may be highly poisonous, pose digestibility challenges, and have not yet been reported to be consumed by primates. Exuded gums and saps are often consumed by primates. Gum is produced by a tree when parasitized or damaged. Sap is transported by living phloem cells, the innermost layer of the tree bark and living tissue to all parts of the tree. Feeding on both of those plant fluids involves different challenges and advantages according to their nature (Nash 1986). Accessibility is variable but gums have the advantages that trees actively produce it in response to insect or mechanical damage. It is easily accessible for all arboreal animals. Saps which circulate in the innermost part of the tree can only be consumed after breakage or after efficient extraction.

Numerous studies report gum consumption in primates, and especially among callithrichines and nocturnal strepsirhines (Coimbra-Filho and Mittermeier 1976; Ramirez et al. 1977; Heymann and Smith 1999; Petter et al. 1971; Charles-Dominique and Petter 1980; Pagès 1980; Bearder and Martin 1980; Nash 1986). Among these gummivorous species, two categories can be distinguished: (1) species that are able to incise the bark of a tree and hence elicit the flow of gum and sap and (2) species that feed by licking or scraping and prising exudate that is already secreted and present on the surface of a bark from a tree. Without dental specializations enabling incising into tree bark, it is almost impossible to exploit sap directly. However, behavioral adaptations may enable primates to exploit sap.

Sap utilization is actually rarely reported in the animal kingdom. Only one group, insects of the Order Hemiptera, includes species that use sap as their dominant dietary component. All Hemiptera are plant feeders, with mouthparts adapted for sucking plant sap from a wide assortment of trees and wild and cultivated plants. Many of them cause injuries or destruction to plants, including fruit trees and grain crops (Wilson 2005). These species have symbiotic micro-organisms in their guts which enable the digestion and assimilation of the nutrients contained in the sap. After digestion and assimilation of ingested sap by the hemipteran gut, the residue is voided via the anus as honeydew, which is often produced in copious amounts. Honeydew is used as food by various animals which can be considered as secondary, proxy sap feeders (Douglas 2006) or cryptic herbivores (Hunt 2003) that exploit the capacity of hemipterans to access plant products. Many invertebrates, including ants, flies, wasps, bees, and butterflies, as well as vertebrates like nectarivorous birds and geckos (Fölling et al. 2001) consume honeydew that has fallen onto plants or other surfaces. Feeding on honeydew depends on its production which can vary seasonally, temporally, and with prevailing weather, but which also may offer a high energy resource during harsh periods of food scarcity. For instance, honeydew is by far the most abundant nectar-like resource in New Zealand's beech forest which is infested by scale insects. The kaka parrot, Nestor 
meridionalis meridionalis, can obtain its daily energy requirement by feeding on honeydew for about $3 \mathrm{~h}$ (Beggs and Wilson 1991).

The flatid planthopper, Phromnia rosea (Order: Hemiptera; Suborder: Auchenorrhyncha; Superfamily: Fulgoroidea; Family: Flatidae), is endemic to Madagascar (see Fig. 7.1). To our knowledge, no clear geographical distribution of this insect has yet been described and it may be a synonym of Flatida coccinea described in the literature (Hladik et al. 1980, ongoing estimation). These insects are nocturnal, living in large colonies, and feeding on the sap of vines (Hladik et al. 1980). Secretions are produced in a liquid form which drops onto leaves and stems. Animals lick or scrape these secretions directly from the vegetation. White wax produced by the hemipteran larvae often abundantly covers the vegetation below the flatid colony. Previous published nutritional analysis showed that honeydew contains a high sugar concentration, but is poor in protein content (Hladik et al. 1980).

Mouse lemurs (Microcebus spp.) are small-bodied nocturnal lemurs that are endemic to Madagascar. Sixteen species have been described to date (Olivieri et al. 2007; Radespiel et al. 2008). Mouse lemurs inhabit all forest habitats (Radespiel 2006). Microcebus murinus (J.F. Miller, 1777), the gray mouse lemur, is the most widespread species. Its distribution ranges from the north-western dry deciduous forest to the spiny forest in southeastern areas (e.g., Mittermeier et al. 2008; Olivieri et al. 2007). It was first described as a solitary foraging omnivore which "occasionally and opportunistically" consumes exuded gums (Martin 1973). It also feeds on insects, fruits, seeds, and leaves (Hladik et al. 1980; Martin 1973; Radespiel et al. 2006). Mouse lemurs are not able to gouge, but collect exuded tree gum by licking and by scraping the bark with the tooth comb. Mouse lemurs are also seen on vines infested by flatid bugs, licking the honeydew secreted by the larvae (Corbin and Schmid 1995). During periods of food scarcity in highly seasonal environments, when foods such as fruits and nectar are absent or less abundant, gum and hemipteran larvae honeydew may represent keystone resources (Génin 2003; Radespiel et al. 2006; Joly and Zimmermann 2007; Dammhahn and Kappeler 2008). However, no systematic
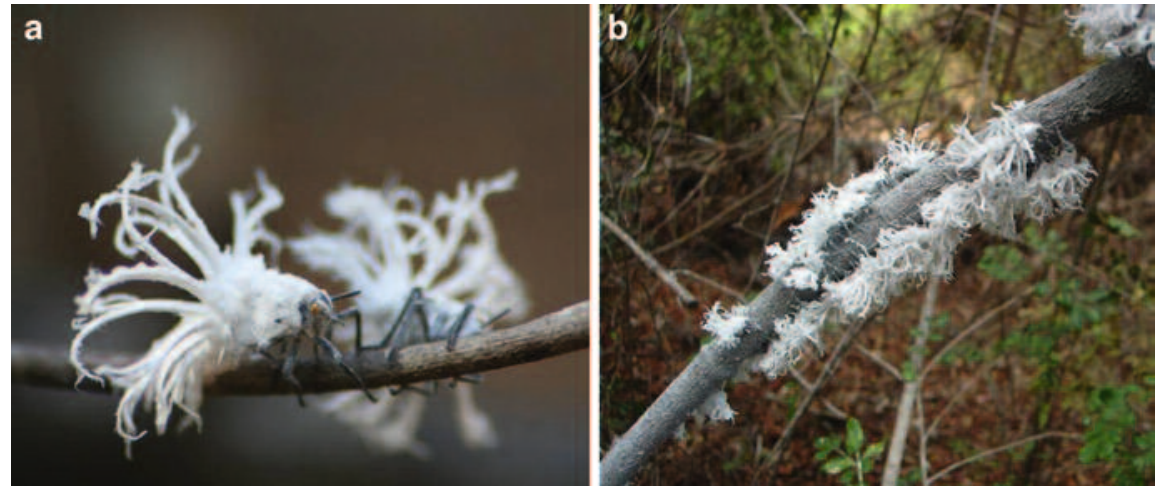

Fig. 7.1 An hemipteran larva of a flatid bug (a). An aggregate of larvae (b) during the dry season in the National Park of Ankarafantsika 
investigation of the seasonality of diet has been performed to evaluate the relative importance of these food resources for the survival of $M$. murinus evolving in different forest types and climate conditions. The goal of this study was thus (1) to assess exudate and honeydew consumption during the dry and the rainy seasons at a geographical location marked by a strong seasonality, (2) to investigate the relative consumption of gum and honeydew across seasons, and (3) to assess foraging strategies when mouse lemurs feed on exudates. We hypothesized that food resource use would vary according to season, that gum and/or honeydew represent keystone food resources during a period of scarcity, and that lemurs revisit productive feeding sites.

\section{Material and Methods}

\section{Study Site and Climate Conditions}

We conducted this study during two consecutive late dry seasons (August-October 2005 and August-October 2006) and the beginning of a rainy season (December 2006-January 2007) in the Ampijoroa Forestry Reserve (64,300 ha) in the dry deciduous forest of the Ankarafantsika National Park in northwestern Madagascar, $110 \mathrm{~km}$ south of Mahajanga. The climate is strongly seasonal with a cool, dry season from May to October and a hot, rainy season from November to April, with heavy rains in January and February (Schmelting et al. 2000, see Fig. 7.2 for climatic data in 2005 and 2006). The mean temperature throughout the year usually fluctuates around $27^{\circ} \mathrm{C}$ with a maximum average temperature of $37^{\circ} \mathrm{C}$ in October-November and a minimum average temperature of $16^{\circ} \mathrm{C}$ in June-July (Schmelting et al. 2000,

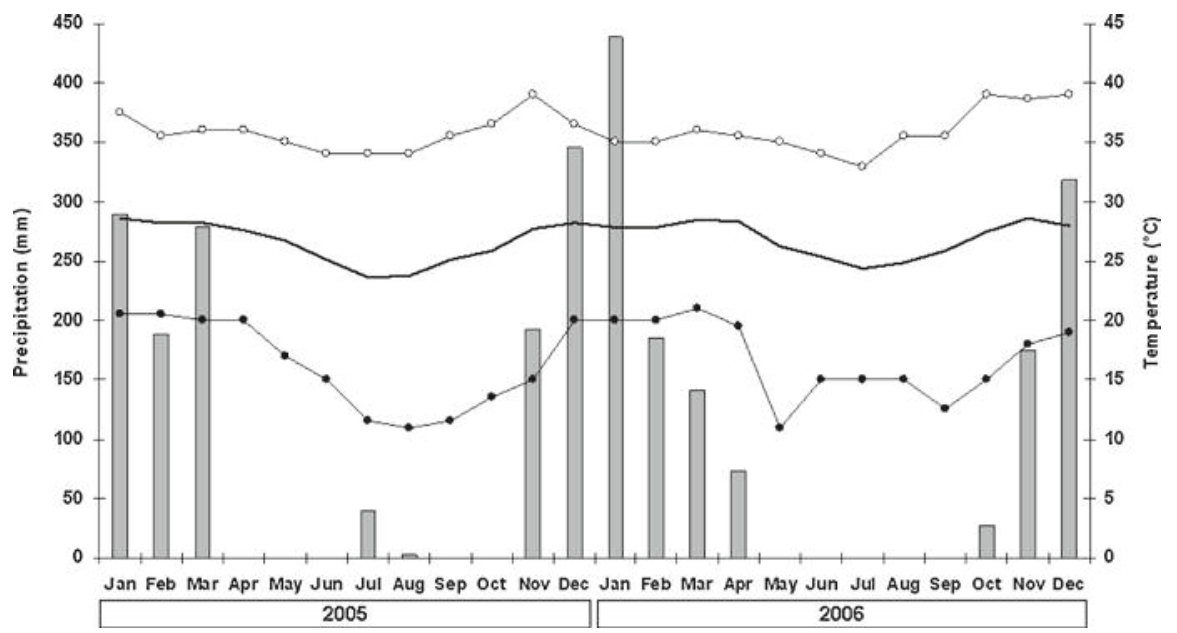

Fig. 7.2 Climatic data at Ampijoroa station in the Ankarafantsika National Park in 2005 and 2006. Monthly rainfall (bars), average monthly mean temperature (plain line), minimal (filled circles), and maximal temperatures (open circles) are represented 
see Fig. 7.2 for 2005 and 2006). Precipitation has a yearly mean of 1,100-1,600 mm (the annual precipitation was 1,337 $\mathrm{mm}$ in 2005 and $1,360 \mathrm{~mm}$ in 2006). We worked in a 30.6 ha forest patch, Jardin Botanique A (JBA; $16^{\circ} 19 \mathrm{~S} 46^{\circ} 48 \mathrm{E}$ ), with a rectangular grid trail system allowing spatial orientation in the forest.

\section{Focal Observation and Analysis}

In 2005, during a routine monthly capture session (Rendigs et al. 2003) a total of five females of M. murinus were captured and equipped with radiocollars (TW4, Biotrack, UK). In 2006, we recaptured and radiocollared two females of the previous year and radiocollared two new females. A total of seven individuals were thus radiocollared across the whole study period. With the help of a portable receiver and an antenna (TR-4 with RA-14K antenna; Telonics Inc, Mesa, AZ), we followed each animal during six consecutive nights between dusk (about 6 p.m.) and midnight (12 p.m.). With a dictaphone, we collected behaviors ad libitum, i.e., by continuously recording the start and end of each behavior bout, according to the focal-animal sampling method (Altmann 1974). The following behavioral categories were recorded: Feeding $=$ an animal ingests a food item, Resting = an animal does not move or sleeps, Locomotion = an animal being in motion, Social interaction=an animal was interacting affiliatively (with another adult congener or during infant care) or agonistically with another congener, and Unknown=it was impossible for the observer to determine the activity of an animal. Additional information was collected concerning the feeding activity. We noted (1) the feeding duration using a chronometer, (2) the food category, and (3) the position of a feeding site with a Global Positioning System (Magellan GPS, Explorist 100; World Geodesic System 84; mean error $10 \mathrm{~m}$ ). We recorded the following major food categories: gum, honeydew, insect, nectar, flower, fruit, seed, and unknown food item. A mouse lemur was considered to be feeding on gum when it was observed biting or licking the stem of trees, on hemipteran larvae secretions when licking the leaves and branches where larvae were present, and on animal prey when chasing, catching, and eating the respective animal item. We recorded nectar, flower, fruit, and seed eating when an animal was seen licking nectar or eating flowers, fruits, and seeds. Unknown food item was recorded when it was impossible for the observer to determine an eaten food item. Each feeding site, defined as a site where the animal stopped to eat one of the items described above, was individually marked with a flag. A site was defined as revisited when it was visited more than once and on different nights. The sleeping site was localized radiotelemetrically during the daytime. Sleeping trees were also individually marked with a flag, and their spatial position determined by GPS coordinates.

\section{Data and Statistical Analysis}

To calculate an activity budget for each animal for each season, we defined as contact time the total period during which we had visual contact with the focal animal. 
For each behavioral category (feeding, resting, locomotion, social interaction, and unknown behavior), we calculated the total duration for each animal. The activity budget was established by calculating the percentage of time an animal spent in each category in relation to the total contact time.

We calculated the percentage of feeding time each animal spent eating each food item (gum, honeydew, insect, nectar, flower, fruit, seed, and unknown food item). For that purpose, we divided the total duration eating a food item by the total time spent feeding for each animal. Descriptions are presented as means across subjects (and ranges). In total, we followed mouse lemurs for $275 \mathrm{~h}$ during the dry season and $70 \mathrm{~h}$ during the rainy season. We pooled the data for both dry seasons together. For the two females that were followed during both dry seasons, we calculated an average over the both periods. During the dry seasons, we followed a total of seven females. The behavioral observations were possible in 56.5\% (range 45.9-75.5\%) of the time an animal spent outside the nest. During the rainy season we lost two females because of predation or emitter defects. Contact time decreased to $35.2 \%$ (range $32.2-36.1 \%$ ), because of heavy rain and dense foliage, which greatly reduced visibility of the focal individual.

To evaluate the location of feeding sites within home ranges of each animal for each season, we used the spatial coordinates given by the GPS of a minimum of 50 independent points, i.e., location of the animal recorded every $30 \mathrm{~min}$, plus the additional feeding sites and sleeping sites where animals were observed. We performed calculations using Animal Movement Software (Hooge et al. 1999) for Arcview GIS 3.3 (ESRI) using the Minimum Convex Polygon method. The statistical tests were performed using Statistica 6.0.

\section{Results}

\section{Activity Budget During the Dry and Rainy Season}

During the dry season, mouse lemurs $(N=7)$ mostly fed and rested (Fig. 7.3). Feeding activity represented $54.2 \%$ (range $21.7-71.2 \%$ ) and resting $41.2 \%$ (range 19.7-68.9\%) of the total contact time. The individuals showed lower locomotor activity $(9.1 \%$ range $4.5-13.5 \%)$ than in the rainy season. During the rainy season, mouse lemurs $(N=3)$ fed less than in the dry season $(27.5 \%$ of the time; range 23.3-37.1\%). Their time in locomotion was $20.8 \%$ (range 19.7-28.6\%) and resting was $17.1 \%$ (range $8.8-41.6 \%$ ) of the contact time.

\section{Food Items Consumed}

During the dry season, mouse lemurs spent most of the time feeding on honeydew (49.8\%; range $0.0-71.8 \%$ ) and gum (43.0\%; range 22.9-89.8\%; Friedman test, 


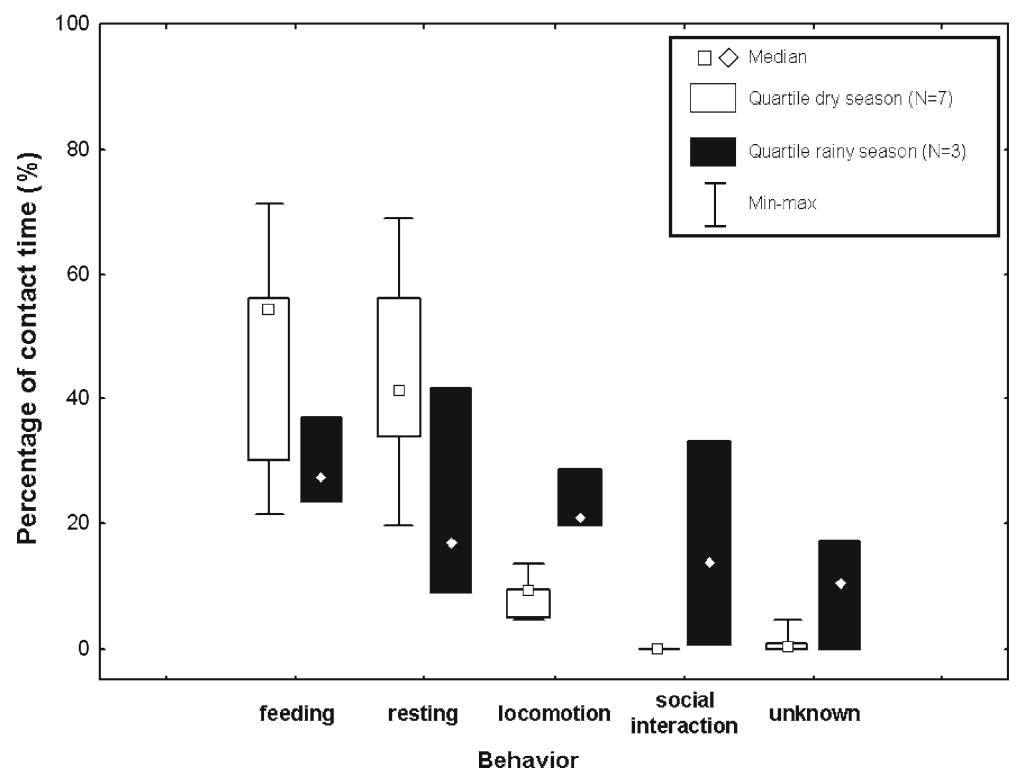

Fig. 7.3 Activity time budget during the dry and the rainy season

$\chi^{2}=36.7, N=7, p<0.00001$; Wilcoxon test, $N=7, p<0.05$; see Fig. 7.4a). Mouse lemurs were never observed feeding directly on the hemipteran larvae. They fed on honeydew by licking the substrate where there were larvae or by picking up dead leaves covered by honeydew from the ground and transporting them up to a higher position in the vegetation to lick the sugar-rich nutrient. We observed great inter-individual variability in feeding time devoted to honeydew: three individuals spent 5.5\% (range 0-8.5\%) on this food item, whereas the other four individuals spent $57.8 \%$ (range 49.8-71.8\%). Animals that spent more time on honeydew foraged within $100 \mathrm{~m}$ of the forest edge, in the eastern part of the study area (Fig. 7.5). The foraging area of the three other individuals was situated in the inner part of the forest (Fig. 7.5).

During the rainy season, we observed a shift in the diet of the focal individuals $(N=3)$. No plant exudate or honeydew consumption was recorded. The subjects spent most of the time feeding on nectar (56.0\%; range: $35.1-89.3 \%$ ) and insects (21.8\%; range: 3.9-53.5\%; Fig. 7.4b). During our observations, mouse lemurs collected nectar from only one species of tree, identified as belonging to the endemic genus Evonymopsis (Family Celastraceae). The nectar largely covered the disc of the flower. It was transparent and very smelly.

\section{Usage of Gum and Honeydew Sites}

We investigated the use of gum and honeydew sites during the dry season. Each female $(N=7)$ visited 25 gum trees (range: 10-37) over the six observation nights 


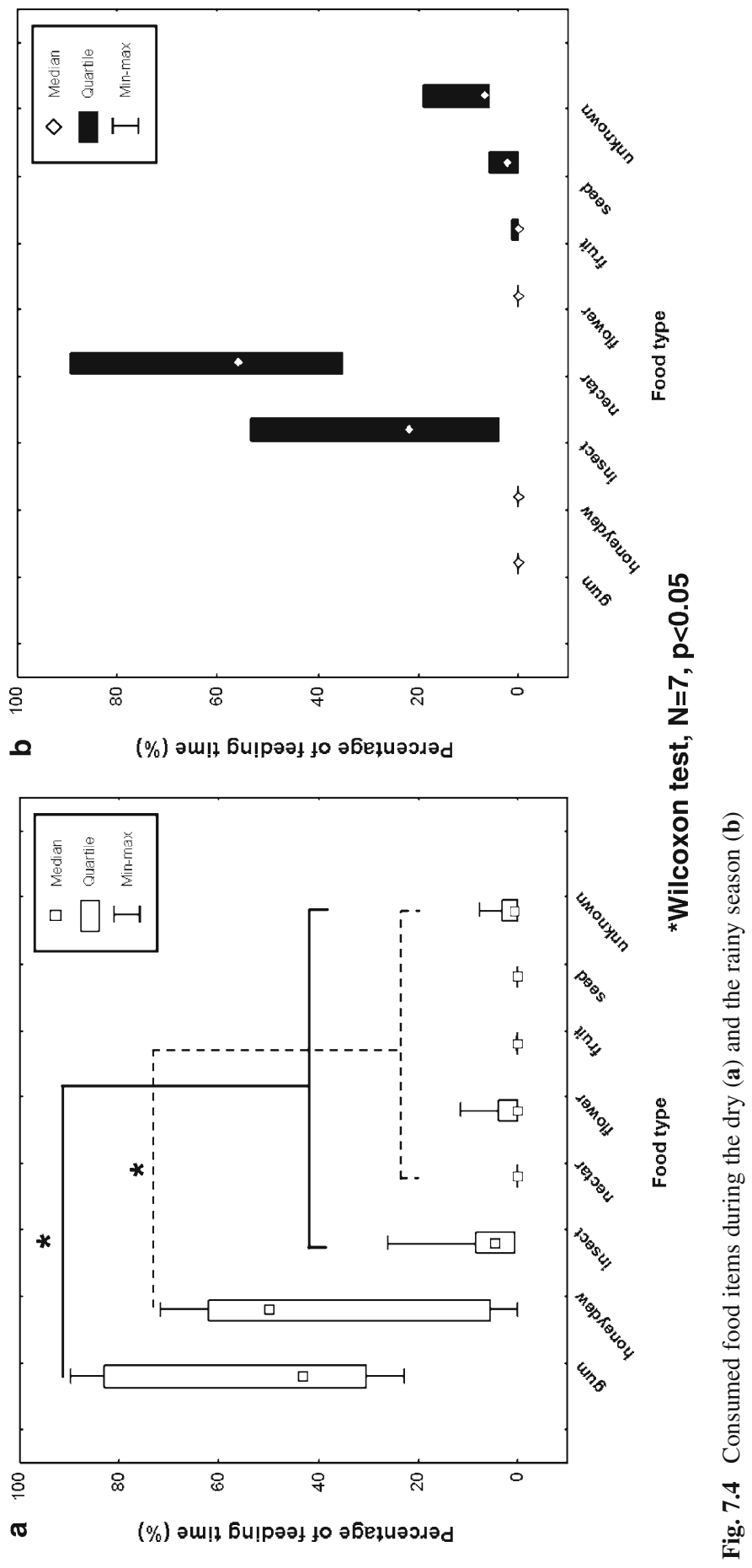




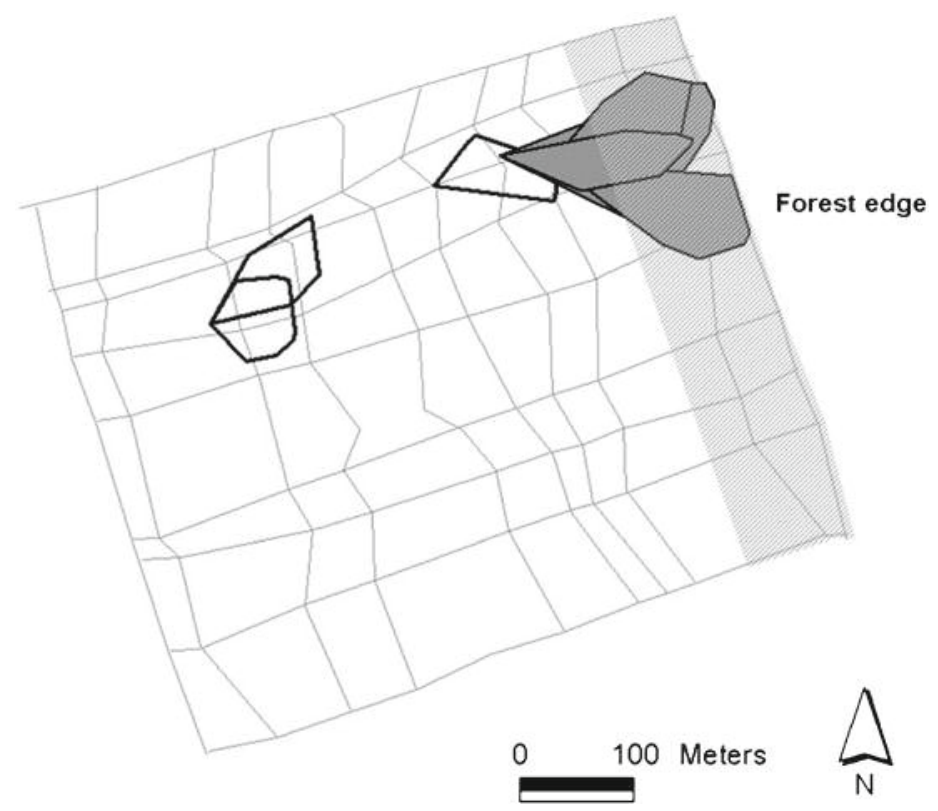

Fig. 7.5 Honeydew consumption and distribution of the home ranges in the study area. Shaded areas were ranges used by females which used more honeydew and white areas were inhabited by females which used mostly gum. Hatched area is forest edge

and revisited $24.3 \%$ of these trees (range: $13.7-46.2 \%$ ) with a frequency of 3.2 visits (range 2.7-7.4) across six nights. The focal animals spent $73.0 \%$ (range: $38.87-80.5 \%$ ) of the gum feeding time on these revisited trees. Six females were observed consuming honeydew and they used 8.5 (range 3-29) different honeydew sites during the six observation nights. Four females revisited honeydew sites (30.3\% of the sites, range $27.3-100 \%$ ). They visited these sites 4.6 times (range $3.4-6$ ) in six nights. They spent $67.6 \%$ (range $63.8-96.9 \%$ ) of the honeydew feeding time on these revisited honeydew sites.

\section{Discussion}

During the dry season, female gray mouse lemurs at Ampijoroa directed their foraging activity mainly on gum trees and sites where honeydew from hemipteran larvae was available. Focal animals exploited some of the sites repeatedly, revisiting them over several nights and spending most of their time feeding on these particular trees. During the rainy season, mouse lemurs shifted their diet. In December and January, they mainly fed on the nectar of shrub flowers and did not feed on gum and honeydew. Exuded gum and sap-derived honeydew thus represented keystone food 
resources for these small-bodied nocturnal primates during periods of seasonal food scarcity in a high seasonal and predictable environment.

Our subjects showed great inter-individual variability in honeydew vs. gum consumption. The diets of mouse lemurs may be influenced by the abundance of food items in their foraging area. The distribution of gum trees may be more or less clumped depending on the species (Nash 1986). In our study area, gray mouse lemurs fed on at least 12 different species of gum trees (see a table of the plant species in Radespiel et al. 2006). In a similar dry deciduous forest (Kirindy), Génin (2003) showed that gum trees from five different species were quite evenly distributed in the forest. Honeydew sites seem, however, to be patchily distributed, mainly depending on the presence of a forest edge. Corbin and Schmid (1995) found a significant difference in the area covered by insect honeydew between the forest edge (within $100 \mathrm{~m}$ ) and the interior of the forest. The larvae of the flatid bug, that produce the honeydew, actually tend to infest a particular plant species Elachyptera minimiflora (Hladik et al. 1980). This plant species mostly occurred in degraded or disturbed areas and logging increased its density (Chouteau 2004). These reports support our observations. We observed that mouse lemurs foraging within $100 \mathrm{~m}$ of the forest edge spent more time feeding on honeydew than gum. In our 30-ha study area, the distribution of honeydew sites may be unequal and may affect the food availability for mouse lemurs. If we consider that gum trees are evenly distributed in our study area and honeydew sites are only present in the forest edge, our focal animals in the forest edge seem to prefer spending time feeding on honeydew vs. gum when both are available.

M. murinus occurs in different forest types (for overview see Radespiel 2006). Our results on seasonal gummivory in $M$. murinus partly coincided with data collected during the same year, 2005, in a western dry deciduous forest, Kirindy (Dammhahn and Kappeler 2008). Although our data collection schedule differed from the latter study (we collected data during the core period of the rainy season instead of the late rainy season), gummivory in M. murinus from Kirindy was also found seasonal. Mouse lemurs used gum mostly during the dry season and the least during the transition between dry and rainy season. Interestingly, the authors reported highest usage of honeydew during this same transition period. To our knowledge no study assessed the activity pattern of flatid bugs larvae yet. However, this would be essential in order to assess the honeydew availability in the different study areas. From personal anecdotal field observations in Ampijoroa, the presence of flatid bug larvae was recorded until the first heavy rainfalls (end OctoberNovember). Colorful pink and winged imagos emerged and dispersed at this period. Gray mouse lemurs living in Mandena, a rainforest in south-east Madagascar, mainly relied on fruits, flowers, and arthropods during the rainy season, the period of food abundance (Lahann 2007). In this study, mouse lemurs only spent $4 \%$ of the feeding events on gum. During the dry season, mouse lemurs enter in torpor in Mandena, there is unfortunately no possibility to have information on seasonal diet, i.e., variation in gummivory or report on honeydew feeding in this study area.

Few reports on gummivory and honeydew feeding of the 16 other mouse lemurs species are available so far. Dammhahn and Kappeler (2008) found that Madame Berthe's mouse lemur, the smallest mouse lemur species, mostly relied on honeydew 
and animal matter all over the year, whereas gummivory was the highest during the dry season. M. berthae's diet was thus not as seasonal as M. murinus's in Kirindy. Génin (2008) demonstrated that M. griseorufus, living in the Berenty Private Reserve, a dry spiny forest of southern Madagascar with highly unpredictable climate condition, did feed on gum during period of droughts. Honeydew feeding was not mentioned in the latter study, but Génin mentioned that "the two most important categories of food" are gum and fruits. Flatid bugs seem to be, however, present in the Berenty reserve since Jolly et al. (2006) observed Lemur catta feeding on larvae secretions. Again, geographical distribution of flatid bugs and their activity pattern is needed to gain insight into a comparative feeding ecology in the different mouse lemur species. In contrast, mouse lemurs living in rainforest habitats seem to be mostly frugivorous and insectivorous (M. rufus, see Atsalis 2008).

Sap feeding by proxy, i.e., honeydew feeding, was mainly described in invertebrates (for review, see Delabie 2001; Douglas 2006; Gullan 1997). In vertebrates, mainly birds and geckos have been observed using honeydew as food resource (birds: see Edwards 1982; Gaze and Clout 1983; Greenberg et al. 1993; Latta et al. 2001, geckos: Fölling et al. 2001). Tending behavior is observed when animals elicit the excretion of droplets by a hemipteran. This exceptional behavior was mostly described for ants (for review, see Delabie 2001) but also for geckos (Fölling et al. 2001). The close interaction between ants and sap-sucking insects was referred as trophobiosis (Hölldobler and Wilson 1990) and indicated a mutualistic relationship (see Delabie 2001). Ants feed on honeydew which contains high concentration of sugar. Ant attendance benefits hemipteran by deterring predators and parasitoids. Ants remove the honeydew which can serve as a substrate for sooty mould and perhaps fungi. However, whereas interactions between ants and sapsucking insects are abundant, their ecological consequences are yet poorly known (for a review see Styrsky and Eubanks 2007). Further investigations are needed for characterising the relationship between the vertebrate users of honeydew and hemipterans. Anecdotes reported that other lemurs (Lemur catta in Jolly et al. 2006, all lemurs in the Kirindy forest in Corbin and Schmid 1995), feed on honeydew. To our knowledge, lemurs seem to be the only mammals using honeydew as a food resource. Whether lemurs demonstrate a tending behavior and to what extent this relationship may be mutualistic and have ecological consequences on the local environment remains unanswered. Future studies should focus on the ecological factors that influence the consequences of honeydew-user/sap-sucking insects to provide greater insight into the role of species interactions in food web dynamics.

Acknowledgments We thank the Commission Tripartite of the Malagasy government, the Département des Eaux et Forêts, and the Association pour la Gestion des Aires for their permission to work in Ampijoroa. We also thank Dr. Daniel Rakotondravony, Faculté des Sciences, Université d'Antananarivo for logistic support. We thank the Durrell Wildlife Preservation Trust for the climatic data. For help in plant identification, we thank Hiroki Sato, University of Kyoto, Japan. For assistance in the field, we thank Dr. Blanchard Randrianambinina, Dr. Solofo Rasoloharijaona, Dr. Marina Scheumann, and Christian Schopf. The study complies with the current laws of Madagascar and was financially supported by the DAAD and financial support for women from the University of Veterinary Medicine Hannover. 


\section{References}

Altmann J (1974) Observational study of behavior: sampling methods. Behaviour 49:227-267

Atsalis S (2008) A natural history of the brown mouse lemur. Prentice Hall, Upper Saddle River, NJ

Bearder SK, Martin RD (1980) Acacia gum and its use by bushbabies, Galago senegalensis (Primates: Lorisidae). Int J Primatol 1:103-128

Beggs JR, Wilson PR (1991) The kaka Nestor meridionalis, a New Zealand parrot endangered by introduced wasps and possums. Biol Cons 56:23-38

Charles-Dominique P, Petter JJ (1980) Ecology and social life of Phaner furcifer. In: CharlesDominique P, Cooper HM, Hladik A, Hladik CM, Pages E, Pariente GF, Petter-Rousseaux A, Petter JJ, Schilling A (eds) Nocturnal Malagasy primates. Academic, New York

Chouteau P (2004) The impacts of logging on the microhabitats used by two species of couas in the western forest of Madagascar. C R Biologies 327:1157-1170

Coimbra-Filho AF, Mittermeier RA (1976) Exudate-eating and tree-gouging in marmosets. Nature 262:630

Corbin GD, Schmid J (1995) Insect secretions determine habitat use patterns by a female lesser mouse lemur (Microcebus murinus). Am J Primatol 37:317-324

Dammhahn M, Kappeler PM (2008) Comparative feeding ecology of sympatric Microcebus berthae and M. murinus. Int J Primatol 29:1567-1589

Delabie JHC (2001) Trophobiosis between Formicidae and Hemiptera (Sternorrhyncha and Auchenorrhyncha): an overview. Neotrop Entomol 30:501-516

Douglas AE (2006) Phloem-sap feeding by animals: problems and solutions. J Exp Bot 57:747-754

Edwards EP (1982) Hummingbirds feeding on an excretion produced by scale insects. Condor $84: 122$

Fölling M, Knogge C, Bohme W (2001) Geckos are milking honeydew-producing planthoppers in Madagascar. J Nat Hist 35:279-284

Gaze PD, Clout MN (1983) Honeydew and its importance to birds in beech forests of South Island, New Zealand. N Z J Ecol 6:33-37

Génin F (2003) Female dominance in competition for gum trees in the grey mouse lemur Microcebus murinus. Rev Ecol (Terre Vie) 58:397-410

Génin F (2008) Life in unpredictable environments: first investigation of the natural history of Microcebus griseorufus. Rev Ecol (Terre Vie) 58:397-410

Greenberg R, Caballero CM, Bichier P (1993) Defense of Homopteran honeydew by birds in the Mexican highlands and other warm temperate forests. Oikos 68:519-524

Gullan PJ (1997) Relationships with ants. In: Ben-Dov Y, Hodgson CJ (eds) Soft scale insects their biology, natural enemies and control. Elsevier Science B.V., Amsterdam

Heymann EW, Smith AC (1999) When to feed on gums: temporal patterns of gummivory in wild tamarins, Saguinus mystax and Saguinus fuscicollis (Callitrichinae). Zoo Biol 18:459-471

Hladik CM, Charles-Dominique P, Petter JJ (1980) Feeding strategies of five nocturnal prosimians in the dry forest of the west coast of Madagascar. In: Charles-Dominique P, Cooper HM, Hladik A, Hladik CM, Pages E, Pariente GF, Petter-Rousseaux A, Petter JJ, Schilling A (eds) Nocturnal Malagasy primates. Academic, New York

Hölldobler B, Wilson EO (1990) The ants. The Belknap Press of the Harvard University Press, Cambridge, MA

Hooge PN, Eichenlaub B, Solomon E (1999) The animal movement program. Version ver. 1.1. USGS, Alaska Biological Science Center, Anchorage

Hunt JH (2003) Cryptic herbivores of the rainforest canopy. Science 300:916-917

Jolly A, Sussman RW, Koyama N, Rasamimanana H (2006) Ringtailed lemur biology. Springer, New York

Joly M, Zimmermann E (2007) First evidence for relocation of stationary food resources during foraging in a strepsirhine primate (Microcebus murinus). Am J Primatol 69:1045-1052 
Lahann P (2007) Feeding ecology and seed dispersal of sympatric cheirogaleid lemurs (Microcebus murinus, Cheirogaleus medius, Cheirogaleus major) in the littoral rainforest of south-east Madagascar. J Zool 271:88-98

Latta SC, Gampedr HA, Tietz JR (2001) Revising the convergence hypothesis of avian use of honeydew: evidence from Dominican subtropical dry season. Oikos 93:250-259

Martin RD (1973) Comparative ecology and behaviour of primates. In: Michael RP, Crook JH (eds) A review of the behaviour and ecology of the lesser mouse lemur (Microcebus murinus). Academic, London

Mittermeier RA, Ganzhorn JU, Konstant WR, Glander K, Tattersall I, Groves CP, Rylands AB, Hapke A, Ratsimbazafy J, Mayor MI, Louis EE, Rumpler Y, Schwitzer C, Rasoloarison RM (2008) Lemur diversity in Madagascar. Int J Primatol 29:1607-1656

Nash LT (1986) Dietary, behavioral, and morphological aspects of gummivory in primates. Am J Physic Anthr 29:113-137

Olivieri G, Randrianambinina B, Rakotondavony D, Zimmermann E, Radespiel U (2007) The ever-increasing diversity in mouse lemurs: three new species in north and northwestern Madagascar. Mol Phyl Evol 43:309-327

Pagès E (1980) Ethoecology of Microcebus coquereli during the dry season. In: CharlesDominique P, Cooper HM, Hladik A, Hladik CM, Pagès E, Pariente GF, Petter-Rousseaux A, Petter JJ, Schilling A (eds) Nocturnal malagasy primates. Academic, New York

Petter JJ, Schilling A, Pariente G (1971) Observations éco-éthologiques sur les deux lémuriens malgaches nocturnes: Phaner furcifer et Microcebus coquereli. La Terre et la Vie 25:287-327

Radespiel U (2006) Ecological diversity and seasonal adaptations of mouse lemurs (Microcebus spp.). In: Gould L, Sauther ML (eds) Lemurs: ecology and adaptation. Springer, New York

Radespiel U, Reimann W, Rahelinirina M, Zimmermann E (2006) Feeding ecology of sympatric mouse lemur species in Northwestern Madagascar. Int J Primatol 27:311-321

Radespiel U, Olivieri G, Rasolofoson DW, Rakotondratsimba G, Rakotonirainy O, Rasoloharijaona S, Randrianambinina B, Ratsimbazafy JH, Ratelolahy F, Randriamboavonjy T, Rasolofoharivelo T, Craul M, Rakotozafy L, Randrianarison RM (2008) Exceptional diversity of mouse lemurs (Microcebus spp.) in the Makira region with the description of one new species. Am J Primatol 70:1033-1046

Ramirez M, Freese CH, Revilla J (1977) Feeding ecology of the pygmy marmoset, Cebuella pygmaea in Northeastern Peru. In: Kleinman DG (ed) The biology and conservation of the Callitrichidae. SI Press, Washington, DC

Rendigs A, Radespiel U, Wrogemann D, Zimmermann E (2003) Relationship between microhabitat structure and distribution of mouse lemurs (Microcebus spp.) in Northwestern Madagascar. Int J Primatol 24:47-64

Schmelting B, Ehresmann P, Lutermann H, Randrianambinina B, Zimmermann E (2000) Reproduction of two sympatric mouse lemur species (Microcebus murinus and M. ravelobensis) in north-west Madagascar: first results of a long-term study. In: Lourenço W, Goodman S (eds) Diversité et endémisme à Madagascar. Société de Biogéographie, Paris

Styrsky JD, Eubanks MD (2007) Ecological consequences of interactions between ants and honeydew-producing insects. Proc Roy Soc B 274:151-164

Wilson SW (2005) Keys to the families of Fulgoromorpha with emphasis on planthoppers of potential economicimportance in the Southeastern United States(Hemiptera:Auchenorrhyncha). Florida Entomol 88:464-481 